\title{
Sağlık Çalışanlarının Hastane Bilgi Sistemi Hakkındaki Görüşleri
}

\author{
Hüseyin Eriş ${ }^{1 *}$, Ebrar Ilıman ${ }^{2}$ \\ ${ }^{1}$ Harran Üniversitesi, Sağlık Hizmetleri MYO, Şanlıurfa, Türkiye (ORCID: 0000-0002-1685-9819) \\ ${ }^{2}$ Cumhuriyet Üniversitesi, Sağlık Hizmetleri MYO, Sivas, Türkiye (ORCID: 0000-0002-5255-8482)
}

(Illk Geliş Tarihi 17 Mayıs 2019 ve Kabul Tarihi 1 Haziran 2019)

(DOI: 10.31590/ejosat.566750)

ATIF/REFERENCE: Eriş, H., \& Ilıman, E. (2019). Sağlık Çalışanlarının Hastane Bilgi Sistemi Hakkındaki Görüşleri. Avrupa Bilim ve Teknoloji Dergisi, (16), 301-309.

\section{Öz}

$\mathrm{Bu}$ araştırmanın amacı, Şanlıurfa ilindeki özel bir hastanede çalışan personelin hastane bilgi sistemi hakkındaki düşüncelerini ve hastane personelinin sosyo demografik özelliklerine göre gruplar arasında farklılık olup olmadığını tespit etmektir. Araştırmanın evrenini Şanlıurfa'daki özel bir hastanede çalışan 410 personel oluşturmaktadır. Örneklem grubu seçilmemiş olup, hastanede tüm personele ulaşılmaya çalışılmış̧ır. Araştırma 01.03.2019 - 30.03.2019 tarihleri arasında yapılmıştır. Araştırma sonucunda anketleri dolduran personel sayısı 290 (\%71) olarak tespit edilmiştir. Verilerdeki eksikliklerden dolayı 11 anket değerlendirme dışı bırakılmış ve 279 anket değerlendirmeye alınmıştır. Araştırmada hastanede çalışan personelin hastane otomasyon kullanım düzeyini tespit etmek amacıyla Venkatesh ve arkadaşlarının (2003) geliştirdiği Birleştirilmiş Teknoloji Kabul ve Kullanım Teorisi (BTKKT) ölçeğinden Engin ve Gürses (2019) tarafindan Türkçe' ye uyarlanan Hastane Bilgi Sistemlerinin Benimsenmesi isimli ölçek kullanılmıştır. Araştırmada kullanılan anketin Cronbach Alpha $(\alpha)$ katsayısı 0,911 ve Hastane Bilgi Sistemleri (HBS) alt boyutlarının ortalaması 3,54 olarak tespit edilmiştir. Hastane personelinin sosyo demografik özelliklerine göre yaş, cinsiyet ve medeni durum değişkenleri açısından gruplar arasında istatistiksel olarak anlamlı bir farklılık tespit edilmemiş, eğitim, meslek ve çalışma süresi bakımından ise gruplar arasında anlamlı farklılık tespit edilmiştir.

Anahtar Kelimeler: Hastane Bilgi Sistemleri, Hastane, Hastane Personeli

\section{Health Workers Views on Hospital Information System}

\begin{abstract}
The aim of this study is to determine the opinions thoughts on hospital Information System of the personnel working in a private hospital in Şanliurfa and whether there is a difference between the groups according to the socio-demographic characteristics of the hospital staff. The universe of the study is consists of 410 staff working in a private hospital in Sanliurfa. The sample group was not selected and all personnel were tried to be reached in the hospital. The study was conducted between 01.03.2019 - 30.03.2019. As a result of the research, the number of personnel filling in the questionnaires was determined as 290 (71\%). Due to the deficiencies in the data, 11 questionnaires were excluded from the evaluation and 279 questionnaires were taken into consideration. In this study, in order to determine the hospital automation usage level of hospital staff, a scale was used to adopt hospital Information Systems adapted to Turkish by Engin and Gürses (2019) from the unified technology acceptance and usage theory (BTKT) scale developed by Venkatesh and his colleagues (2003). The Cronbach Alpha $(\alpha)$ coefficient of the survey was 0.911 and the average of Hospital Information Systems (HBS) subscales was 3.54. There wasn't statistically significant difference between the groups in terms of age, gender and marital status variables according to the socio-demographic characteristics of the hospital staff. However, there was a significant difference between the groups in terms of education, profession and working time.
\end{abstract}

\footnotetext{
* Sorumlu Yazar: Harran Üniversitesi, Sağlık Hizmetleri MYO, Şanlıurfa, Türkiye (ORCID: 0000-0002-1685-9819), erișharran@hotmail.com
} 
Keywords: Health Information Systems (HIS), Healthcare Organization, Health Staff

\section{Giriș}

Bilişim teknolojileri ve bilişim sistemlerinin yaşamın her alanında yer almaya başlaması sonucunda teknoloji çağı diye tabir edilen bir döneme girdi insanoğlu. Basit hesaplamalarla başlayan bu teknoloji dönemi artık cep telefonları ile kıtalar arası görüşmelerden banka hesaplarında işlem yapmaya, gezegenler arası yolculuk hesaplamalarından, insan sağlığı ile ilgili önemli teknolojik cihaz yapımına kadar hayatın tüm alanına girmiş durumdadır.

Günümüzde, bilgi ve iletişim teknolojilerinin yaygın kullanımı, sağlık sektörü de dahil olmak üzere yaşamın hemen hemen tüm yönlerine nüfuz etmiş durumdadır (Biçer, 2018; Bilgiç ve Şendir, 2014; Almunawar ve Anshari, 2012). Sağlam ve güvenilir bilgi, tüm sağlık sistemi yapı taşlarında karar vermenin temelidir ve sağlık sistemi politikası geliştirme ve uygulama, yönetim ve düzenleme, sağlık araştırması, insan kaynakları geliştirme, sağlık eğitimi, hizmet sunumu ve finansmanı için gereklidir (WHO, 2008). Bilişimin sağlığa entegre edilmesi ile bilişim teknolojileri alanında yapılan çalışmalar özellikle 1990'lardan itibaren hem ulusal hem uluslararası platformda artmaya başlamışıı (Uysal ve Arkadaşları, 2017).

Hızlı gelişen teknolojik hayat insan sağlığını da doğrudan etkilemeye başlamıştır. Hastaneler başta olmak üzere birçok sağlık kurumunda hastaların her türlü tetkik, teşhis işlemlerinin yanı sıra hastalara ait bilgilere gerek sağlık kurumu içerisinden gerekse dışından ulaşılabilir bir hale gelmiş̧ir (Gencer ve Arkadaşları, 2019). Hatta başka bir bölgeden akıllı robotlar sayesinde hastayı uzaktan ameliyat edebilme imkanı bile sunar hale gelmiştir. Gelişen teknoloji ile hastane bilgi sistemleri, kurumun kendisi başta olmak üzere sağlık hizmeti sunumunda hastalara ve sağlı profesyonellerine sağlayacağı faydaların, geçmiş tecrübelerden de yararlanılarak daha ileri boyutlarda ve hızlı bir şekilde paydaşlara sunumunun sağlanmasına imkan sunmaktadır (Gundak ve Çetin, 2015; Öner, 2014; Özata ve Aslan, 2004).

Sağlık alanında yıllardır kullanılmaya başlanan bu teknolojik uygulamaları tanımlamak için birtakım terimler kullanılmaya başlanmıştır. $\mathrm{Bu}$ terimler arasında en çok kullanılanları Otomatik Sağlık Kayıtları (OSK), Hastane Bilgi Sistemleri (HBS), Elektronik Hasta Kayıtları (EHK), Elektronik Tıbbi Kayıtlar (ETK), Bilgisayarlı Hasta Kayıtları (BHK) ve Elektronik Sağlık Kayıtları (ESK)'dır (Eriş, 2016; Gundak ve Çetin, 2015; WHO, 2006).

\section{Hastane Bilgi Sistemleri}

Köksal ve Esatoğlu'na göre (2005) HBS, hastanelerde sunulan sağlık hizmetlerinin bilgisayar, notebook, cep telefonu gibi elektronik cihazlar aracılığı ile gerçekleştirilmesi, elektronik ortamda bilgi alışverişinin otomatik olarak yapılması, tıbbi, finansal ve mali hizmetler açısından ortaya çıkan detaylı bilgilerin farklı elektronik cihazlara dayalı bir enformasyon sistemi ile kayıt altına alınıp, bilgiye dönüştürme işlemi olarak tanımlanmaktadır. İdari ve tıbbi bilgileri iç içe, bir arada tutabilen sistemlere bütünleşik HBS denilmektedir (Yılmaz ve Aloğlu, 2002). Başka bir tanımda HBS, sağlık alanında derlenen her türlü verinin kaydedilmesi, toplanması ve ihtiyaca uygun bir şekilde işlenerek kullanıma hazır hale getirilmesi ve sağlık hizmetlerinin etkili ve verimli bir şekilde sunumunu sağlayacak bilgi sistemleri olarak tanımlanmaktadır (Öner, 2014; Işık ve Akbolat, 2010). Başka bir tanımda HBS, hastanelerin çeşitli düzeylerindeki karar mercilerine yardımcı olmak için bilgi toplama ve bilgi iletme işlevlerini yerine getiren, farklı kaynaklardan ulaşılan verileri bütünleyebilme sistemidir (Ak, 2010).

Dünya Sağlık Örgütü'nün sağlık tanımından yola çıkarak, bilişim teknolojilerini bireyin fiziksel, ruhsal ve sosyal yapısını negatif olarak etkileyebilecek her çeşit rahatsızlığı önceden saptayabilecek ya da tedbir alabilecek tahminlerin tespitinde kullanabilme olanağı da, sağlık bilişim sistemlerinin geliş̧mesinde etkili olmuştur (WHO, 2008). Ayrıca hastaneler, kaliteyi arttırmak ve sonuçların iyileşmesini sağlayabilmek için HBS teknolojisine yatırım yapmaktadırlar (Sarnikar ve Murphy, 2009)

HBS, hastanelerin kurumsal yapılarına göre farklı amaçlara hizmet edecek ve verimliliği artıracak şekilde entegre edilebilmektedir (Yılmaz ve Demirkan, 2012). HBS hastanelerde birçok alanda kullanılmaktadır. En çok kullanılan alanlar hastaya ait tıbbi kayitlar (klinik, laboratuvar, radyoloji, ameliyathane, eczane, terapi ve diyet gibi), teletıp, hemşire bilgi sistemleri, hastanenin stratejik planlaması, sağlık pazarlama ve hizmet geliştirme, hastanenin her türlü mali işlemleri (finansal kaynaklar, medikal faturalandırma, personel giderleri vb.), satın alma ve stok değerleme, insan kaynakları yönetimi, devlet kurumları ile iletişim kurma (sağlık bakanlığı, sosyal güvenlik kurumu gibi), hastane yönetim gibi alanlar örnek olarak verilebilir (Kılıçarslan, 2018; Özel ve Arkadaşları, 2014; Top ve Gider, 2012; Işık ve Akbolat, 2010; Kuperman ve Arkadaşları, 2000; Ömürbek ve Altın, 2009). Bu sayede, ihtiyaç duyulan bilgiye kısa sürede, hızlı ve güvenilir bir şekilde ulaşarak, her türlü gereksinimlerini kolayca karşılayabilmektedirler.

\section{Materyal ve Metot}

\subsection{Araştırmanın amacı}

Bu araştırmanın amacı, Şanlıurfa ilindeki özel bir hastanede çalışan personelin hastane bilgi sistemi hakkındaki düşüncelerini ve sosyo demografik özelliklerine göre hastane bilgi sistemi hakkındaki düşüncelerinde farklılık olup olmadığını tespit etmektir. 


\subsection{Araştırmanın Evren ve Örneklemi}

Araştırmanın evrenini Şanlıurfa'daki özel bir hastanede çalışan 410 personel oluşturmaktadır. Örneklem grubu seçilmemiş olup, hastanede hizmet veren tüm personele ulaşılmaya çalışılmıştır. Araştırma 01.03.2019 - 30.03.2019 tarihleri arasında yapılmıştır. Araştırma sonucunda anketleri dolduran personel sayısı $290(\% 71)$ olarak tespit edilmiştir. Verilerdeki eksikliklerden dolayı 11 anket değerlendirme dışı bırakılmış ve 279 anket değerlendirmeye alınmıştır.

\subsection{Veri Toplama Aracı}

Şanlıurfa ilindeki özel bir hastanede çalışan personelin hastane otomasyon kullanım düzeyini tespit etmek amacıyla Venkatesh ve arkadaşlarının (2003) geliştirdiği Birleştirilmiş Teknoloji Kabul ve Kullanım Teorisi (BTKKT) ölçeğinden Engin ve Gürses (2019) tarafından Türkçe' ye uyarlanan, Hastane Bilgi Sistemlerinin Benimsenmesi isimli ölçek kullanılmıştır. Anket iki bölümden oluşmaktadır. Birinci bölümde hastane personelinin sosyo - demografik özelliklerini içeren sorular yer almaktadır. İkinci bölümde ise, 6 alt boyuttan ve toplam 21 ifadeden oluşan Hastane Bilgi Sistemlerinin Benimsenmesi isimli anket kullanılmıştır.

Ankette yer alan her bir ifade 5'li Likert ölçeğine göre hazırlanmış olup; "Kesinlikle Katılmıyorum (1)", "Katılmıyorum (2)", "Kararsızım (3)", "Katılıyorum (4)" ve "Kesinlikle Katılıyorum (5)" ifadelerine yer verilerek oluşturulmuştur.

Anket çalışmasında verilerin ait oldukları aralıklar belirlenirken (Üst Değer-Alt Değer)/Değer Sayısı formülü kullanılmıştır. Aralık değerleri Tablol'de görülmektedir.

Tablo 1. Aritmetik Ortalamaları Değerlendirme Tablosu

\begin{tabular}{l|c|c}
\hline Aralık & Seçenekler & Aralık Değeri \\
\hline $1.00-1.80$. & Kesinlikle Katılmıyorum & Çok olumsuz \\
\hline $1.81 .-2.60$ & Katılmıyorum & Olumsuz \\
\hline $2.61-3.40$ & Kararsızım & Orta \\
\hline $3.41-4.20$ & Katılıyorum & Olumlu \\
\hline $4.21-5.00$ & Kesinlikle Katılıyorum & Çok olumlu \\
\hline
\end{tabular}

Araştırmada kullanılan anketin Cronbach Alpha $(\alpha)$ katsayısı 0,911'dir. Cronbach $\alpha$ değerinin 0.7'den büyük olması kullanılan ölçme aracının güvenilir olduğunu gösterir.

\section{Bulgular}

Bu bölümde araştırma sonunca elde edilen bulgular verilmektedir. Tablo 2'de araştırmaya katılan hastane personelinin sosyo demografik bilgileri verilmiştir.

Tablo 2. Araştırmaya Katılan Hastane Personelinin Sosyo-Demografik Bilgileri

\begin{tabular}{l|l|c|c}
\hline & Demografik Gruplar & $\mathbf{N}$ & $\mathbf{\%}$ \\
\hline \multirow{3}{*}{ Cinsiyet } & Kadın & 148 & 53,3 \\
& Erkek & 131 & 46,7 \\
& Toplam & $\mathbf{2 7 9}$ & $\mathbf{1 0 0 , 0}$ \\
\hline Yaş grupları & $18-24$ yaş & 53 & 19,0 \\
& 25-34 yaş & 159 & 57,1 \\
& 35 yaş -üstü & 67 & 23,9 \\
& Toplam & $\mathbf{2 7 9}$ & $\mathbf{1 0 0 , 0}$ \\
\hline Medeni durum & Evli & 126 & 45,1 \\
& Bekar & 153 & 54,9 \\
& Toplam & $\mathbf{2 7 9}$ & $\mathbf{1 0 0 , 0}$ \\
\hline Eğitim durumu & Lise/Ön lisans & 114 & 41,0 \\
& Lisans & 135 & 48,0 \\
& Lisansüstü/Doktora & 30 & 11,0 \\
Meslek & Toplam & $\mathbf{2 7 9}$ & $\mathbf{1 0 0 , 0}$ \\
& Doktor & 25 & 9,0 \\
& Hemşire/Ebe & 140 & 50,2 \\
\hline Çalışma süresi & Tibbi sekreter & 114 & 40,8 \\
e-ISSN: 2148-2683 & Toplam & $\mathbf{2 7 9}$ & $\mathbf{1 0 0 , 0}$ \\
\hline
\end{tabular}


Araştırmaya katılan personelin \%53,3'ü kadın, \%57,1'i 25-34 yaş grubunda, \%54,9'u bekar, \%36,1'i lisans mezunu, \%60,5'i 1999 TL- altı grubunda gelire sahip, \%40,8'i tıbbi sekreter, \%38,8’i 3-10 yıldır çalışma süresi grubunda, \%38,6'si 3-10 yıl mesleki tecrübe grubunda, \%54,2'si 3-10 yıl bilgisayar tecrübesi grubunda ve \%44,5'i 3-10 yıl hastane HBS tecrübesi grubunda yer almaktadir.

Tablo 3. HBS Ifadelerine Verilen Cevapların Ortalamalart

\begin{tabular}{|c|c|c|c|c|}
\hline Performans Beklentisi & $\mathbf{N}$ & Ort. & S.S. & $\begin{array}{l}\text { Aralık } \\
\text { Değeri }\end{array}$ \\
\hline HBS'yi kullanmayı ișimde yararlı buluyorum. & 226 & 3,92 & 1,04 & \multirow{5}{*}{ Olumlu } \\
\hline HBS'yi kullanmak işlerimdeki başarıyı arttırır. & 220 & 4,00 & 0,99 & \\
\hline HBS'yi işlerimi daha çabuk yapmama yardımcı olur. & 222 & 3,99 & 1,09 & \\
\hline HBS'yi kullanmak iş verimliliğimi arttırır. & 209 & 3,93 & 1,13 & \\
\hline Toplam & 226 & 3,96 & $\mathbf{0 , 9 3}$ & \\
\hline Efor Beklentisi & $\mathrm{N}$ & Ort. & S.S. & \multirow{6}{*}{ Olumlu } \\
\hline HBS’yi nasıl kullanılacağını öğrenmek benim için kolaydır. & 220 & 3,69 & 1,11 & \\
\hline HBS’yi kullanmayı açık ve anlaşılabilir buluyorum. & 223 & 3,43 & 1,17 & \\
\hline HBS'yi kullanmayı kolay buluyorum. & 224 & 3,35 & 1,09 & \\
\hline HBS kullanımında ustalaşmak benim için kolaydır. & 224 & 3,67 & 1,02 & \\
\hline Toplam & 226 & $\mathbf{3 , 5 1}$ & $\mathbf{0 , 9 2}$ & \\
\hline Sosyal Etki & $\mathrm{N}$ & Ort. & S.S. & \multirow{5}{*}{ Olumlu } \\
\hline İş arkadaşlarım HBS'yi kullanmam gerektiğini düşünmektedir. & 219 & 3,56 & 1,09 & \\
\hline Üst yöneticilerim HBS'yi kullanmam gerektiğini düşünmektedir. & 219 & 3,64 & 1,15 & \\
\hline HBS kullanımında insanların görüşlerine önem veririm. & 219 & 3,56 & 1,15 & \\
\hline Toplam & 224 & $\mathbf{3 , 5 9}$ & $\mathbf{0 , 9 3}$ & \\
\hline Kolaylaştırıcı Koşullar & $\mathrm{N}$ & Ort. & S.S. & \multirow{7}{*}{ Orta } \\
\hline HBS'yi kullanmada gerekli kaynaklara sahibim. & 224 & 3,29 & 1,13 & \\
\hline HBS'yi kullanma noktasında gerekli bilgiye sahibim. & 224 & 3,50 & 1,02 & \\
\hline HBS'yi kullandığım diğer teknolojilerle uyumludur. & 223 & 3,30 & 1,08 & \\
\hline HBS'yi kullanırken zorlandığımda yardım alacak birilerini bulabilirim. & 223 & 3,34 & 1,16 & \\
\hline Sisteme destek veren ekip konusunda uzmandır. & 224 & 3,29 & 1,17 & \\
\hline Toplam & 227 & 3,34 & $\mathbf{0 , 8 6}$ & \\
\hline Davranışsal Niyet & $\mathrm{N}$ & Ort. & S.S. & \multirow{5}{*}{ Orta } \\
\hline Gelecekte de HBS'yi kullanmaya devam etme niyetindeyim. & 223 & 3,29 & 1,09 & \\
\hline HBS’yi her zaman kullanmaya çalışacağım. & 224 & 3,33 & 1,00 & \\
\hline HBS'yi yoğun şekilde kullanmaya devam etmeyi planlıyorum. & 223 & 3,22 & 1,08 & \\
\hline Toplam & 227 & 3,27 & $\mathbf{0 , 9 5}$ & \\
\hline HBS Kullanım Boyutu & $\mathrm{N}$ & Ort. & S.S. & \multirow{5}{*}{ Olumlu } \\
\hline HBS'yi kullanmaya çok zaman ayırıyorum. & 221 & 3,45 & 1,14 & \\
\hline HBS'yi çok sık kullanıorum. & 224 & 3,73 & 1,20 & \\
\hline Toplam & 224 & 3,60 & 1,10 & \\
\hline Genel Performans Beklentisi & 227 & $\mathbf{3 , 5 4}$ & 0,64 & \\
\hline
\end{tabular}

HBS ifadelerine verilen cevapların ortalamaları tablo 3'de verilmiştir. Tabloya bakıldığında, HBS alt boyutlarının ortalamalarının genel toplamı 3,54 olarak tespit edilmiş ve hastane personelinin genel olarak HBS genel performans beklentisine katıldı̆̆ görülmüştür. HBS alt boyutlarının ortalamalarının toplamına bakıldığında; "Performans Beklentisi" alt boyutunun toplam ortalaması 3,96, "Efor Beklentisi" alt boyutunun toplam ortalaması 3,51, "Sosyal Etki" alt boyutunun toplam ortalaması 3,59 ve "Kullanım Boyutu" alt boyutunun toplam ortalaması 3,60 olarak belirlenmiştir. Bu verilere göre hastane personelinin bu alt boyutlara genel olarak yüksek oranda katıldıkları tespit edilmiştir. 
HBS alt boyutlarından "Kolaylaştırıcı Koşullar" alt boyutunun toplam ortalaması 3,34 ve "Davranışsal Niyet” alt boyutunun toplam ortalaması 3,27 olarak belirlenmiştir. Bu verilere göre hastane personelinin bu alt boyutlar konusunda genel olarak kararsız oldukları görülmektedir.

Araştırmada, hastanede çalışan personelin sosyo demografik özelliklerine göre gruplar arasında istatistiksel olarak anlamlı farklılık olup olmadığını tespit etmek amacıyla yapılan ANOVA ve Tukey testine göre yaş, cinsiyet ve medeni durum değişkenleri açısından gruplar arasında istatistiksel olarak anlamlı bir farklılık tespit edilmemiştir. Bu nedenle bu değişkenlere ait tablolar burada verilmemiştir.

Tablo.4 HBS Alt Boyutlarının Ĕgitim Durumu Değişkeni Bakımından İncelenmesi

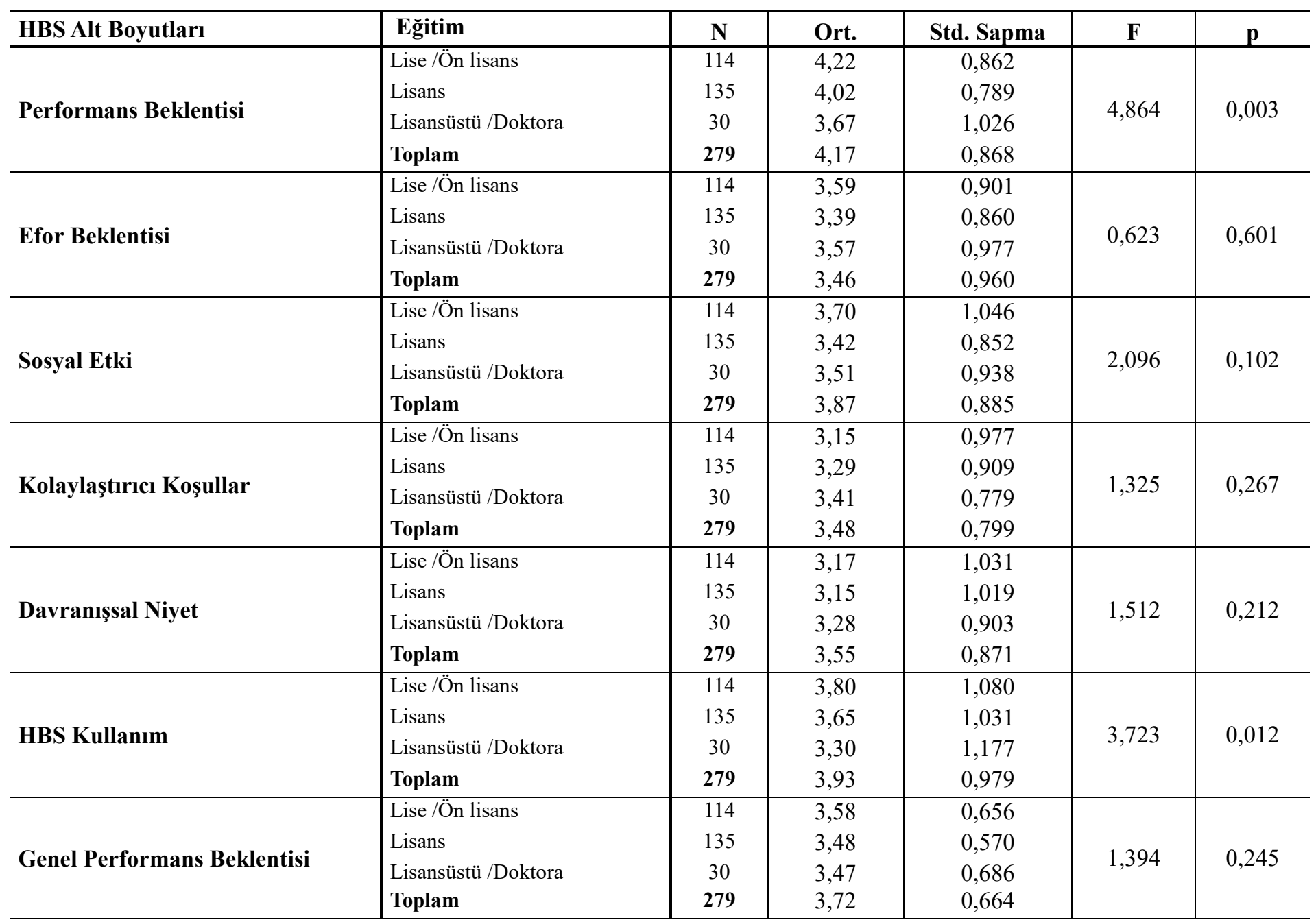

HBS alt boyutlarının eğitim durumu değişkeni bakımından incelenmesi Tablo 4'de verilmiştir. ANOVA testine göre HBS alt boyutlarından sadece performans beklentisi ve kullanım boyutlarında istatistiksel olarak anlamlı fark bulunmuştur. Farklılı̆̆ın kaynağını belirlemek için yapılan Tukey testine göre aşağıdaki bulgular elde edilmiştir.

1. Performans beklentisi boyutunda farklılık, Lise/önlisans ile Lisans ve Lisansüstü /Doktora ile Lisans gruplarının ortalamalarının farklı olmasından kaynaklanmaktadır.

2. Kullanım boyutunda farklılık, Lisansüstü/Doktora ile Lisans gruplarının ortalamalarının farklı olmasından kaynaklanmaktadır.

Tablo. 5 HBS Alt Boyutlarının Meslek Değişkeni Bakımından İncelenmesi

\begin{tabular}{l|l} 
N & Ort.
\end{tabular}




\begin{tabular}{|c|c|c|c|c|c|c|}
\hline Performans Beklentisi & $\begin{array}{l}\text { Doktor } \\
\text { Hemşire/Ebe } \\
\text { Tibbi sekreter } \\
\text { Toplam }\end{array}$ & $\begin{array}{c}25 \\
140 \\
114 \\
279\end{array}$ & $\begin{array}{l}4,15 \\
3,56 \\
4,13 \\
3,97\end{array}$ & $\begin{array}{l}0,861 \\
0,912 \\
0,777 \\
0,877\end{array}$ & 7,220 & 0,001 \\
\hline Efor Beklentisi & $\begin{array}{l}\text { Doktor } \\
\text { Hemşire/Ebe } \\
\text { Tibbi sekreter } \\
\text { Toplam }\end{array}$ & $\begin{array}{c}25 \\
140 \\
114 \\
279\end{array}$ & $\begin{array}{l}3,48 \\
3,37 \\
3,54 \\
3,47\end{array}$ & $\begin{array}{l}1,051 \\
0,988 \\
0,884 \\
0,960\end{array}$ & 0,385 & 0,681 \\
\hline Sosyal Etki & $\begin{array}{l}\text { Doktor } \\
\text { Hemşire/Ebe } \\
\text { Trbbi sekreter } \\
\text { Toplam }\end{array}$ & $\begin{array}{c}25 \\
140 \\
114 \\
279\end{array}$ & $\begin{array}{l}3,90 \\
3,37 \\
3,47 \\
3,57\end{array}$ & $\begin{array}{l}0,830 \\
0,966 \\
0,929 \\
0,932\end{array}$ & 4,034 & 0,020 \\
\hline Kolaylaştırıcı Koşullar & $\begin{array}{l}\text { Doktor } \\
\text { Hemşire/Ebe } \\
\text { Tibbi sekreter } \\
\text { Toplam }\end{array}$ & $\begin{array}{c}25 \\
140 \\
114 \\
279 \\
\end{array}$ & $\begin{array}{l}3,45 \\
3,17 \\
3,38 \\
3,34 \\
\end{array}$ & $\begin{array}{l}0,788 \\
0,711 \\
0,933 \\
0,835 \\
\end{array}$ & 1,336 & 0,266 \\
\hline Davranışsal Niyet & $\begin{array}{l}\text { Doktor } \\
\text { Hemşire/Ebe } \\
\text { T1bbi sekreter } \\
\text { Toplam }\end{array}$ & $\begin{array}{c}25 \\
140 \\
114 \\
279\end{array}$ & $\begin{array}{l}3,53 \\
3,21 \\
3,34 \\
3,36\end{array}$ & $\begin{array}{l}0,790 \\
0,864 \\
0,982 \\
0,899\end{array}$ & 1,342 & 0,265 \\
\hline HBS Kullanım & $\begin{array}{l}\text { Doktor } \\
\text { Hemşire/Ebe } \\
\text { Tibbi sekreter } \\
\text { Toplam }\end{array}$ & $\begin{array}{c}25 \\
140 \\
114 \\
279\end{array}$ & $\begin{array}{l}3,85 \\
3,07 \\
3,82 \\
3,61\end{array}$ & $\begin{array}{l}0,978 \\
1,034 \\
0,913 \\
1,020\end{array}$ & 8,980 & 0,000 \\
\hline Genel Performans Beklentisi & $\begin{array}{l}\text { Doktor } \\
\text { Hemşire/Ebe } \\
\text { Tibbi sekreter } \\
\text { Toplam }\end{array}$ & $\begin{array}{c}25 \\
140 \\
114 \\
279\end{array}$ & $\begin{array}{l}3,71 \\
3,31 \\
3,60 \\
3,55\end{array}$ & $\begin{array}{l}0,649 \\
0,628 \\
0,602 \\
0,639\end{array}$ & 4,678 & 0,011 \\
\hline
\end{tabular}

HBS alt boyutlarının eğitim durumu değişkeni bakımından incelenmesi Tablo 5'de verilmiştir. ANOVA testine göre HBS alt boyutlarından performans beklentisi, sosyal etki, kullanım ve genel performans beklentisi boyutlarında istatistiksel olarak anlamlı fark bulunmuştur. Farklılığın kaynağını belirlemek için yapılan Tukey testine göre aşağıdaki bulgular elde edilmiştir.

1. Performans beklentisi alt boyutunda farklılık, hemşire ile doktor ve hemşire ile tıbbi sekreter gruplarının ortalamalarının farklı olmasından kaynaklanmaktadır.

2. Sosyal etki alt boyutunda farklılık hemşire ile doktor gruplarının ortalamalarının farklı olmasından kaynaklanmaktadır.

3. Kullanım alt boyutunda farklılık, hemşire ile doktor ve hemşire ile tıbbi sekreter gruplarının ortalamalarının farklı olmasından kaynaklanmaktadır.

4. Genel Performans beklentisi alt boyutunda farklılık hemşire ile doktor gruplarının ortalamalarının farklı olmasından kaynaklanmaktadır.

Tablo.6 HBS Alt Boyutlarının Çalışma Süresi Değişkeni Bakımından İncelenmesi

\begin{tabular}{|c|c|c|c|c|c|c|}
\hline & Çalışma süresi & $\mathrm{N}$ & Ort. & Std. Sapma & $\mathrm{F}$ & $\mathrm{p}$ \\
\hline \multirow{3}{*}{ Performans Beklentisi } & $1-3$ y1l & 98 & 4,10 & 0,913 & \multirow{3}{*}{3,149} & \multirow{3}{*}{0,026} \\
\hline & 3-10 y1l & 109 & 3,86 & 0,928 & & \\
\hline & Toplam & 279 & 3,95 & 0,929 & & \\
\hline \multirow{3}{*}{ Efor Beklentisi } & $1-3$ yil & 98 & 3,50 & 0,874 & \multirow{3}{*}{3,643} & \multirow{3}{*}{0,014} \\
\hline & 3-10 y1l & 109 & 3,62 & 0,797 & & \\
\hline & Toplam & 279 & 3,51 & 0,929 & & \\
\hline Sosyal Etki & $1-3$ y1l & 98 & 3,66 & 1,036 & 1,583 & 0,194 \\
\hline
\end{tabular}




\begin{tabular}{|c|c|c|c|c|c|c|}
\hline & \begin{tabular}{|l|}
$3-10$ yll \\
10 yll -üstü \\
Toplam
\end{tabular} & $\begin{array}{c}109 \\
72 \\
\mathbf{2 7 9} \\
\end{array}$ & $\begin{array}{l}3,57 \\
3,69 \\
3,59 \\
\end{array}$ & $\begin{array}{l}0,823 \\
0,927 \\
0,943 \\
\end{array}$ & & \\
\hline Kolaylaştırıcı Koşullar & $\begin{array}{l}1-3 \text { y1l } \\
3-10 \text { y1l } \\
10 \text { y1l -üstü } \\
\text { Toplam }\end{array}$ & $\begin{array}{c}98 \\
109 \\
72 \\
\mathbf{2 7 9}\end{array}$ & $\begin{array}{l}3,29 \\
3,37 \\
3,35 \\
3,33\end{array}$ & $\begin{array}{l}0,851 \\
0,790 \\
0,950 \\
0,861\end{array}$ & 0,224 & 0,879 \\
\hline Davranışsal Niyet & \begin{tabular}{|l|}
$1-3$ y1l \\
$3-10$ y1l \\
10 yıl -üstü \\
Toplam \\
\end{tabular} & $\begin{array}{c}98 \\
109 \\
72 \\
\mathbf{2 7 9} \\
\end{array}$ & $\begin{array}{l}3,32 \\
3,30 \\
3,25 \\
3,26 \\
\end{array}$ & $\begin{array}{l}0,933 \\
0,889 \\
1,038 \\
0,960\end{array}$ & 0,623 & 0,601 \\
\hline HBS Kullanım & \begin{tabular}{|l|}
$1-3$ y1l \\
$3-10$ y1l \\
10 y1l -üstü \\
Toplam \\
\end{tabular} & $\begin{array}{c}98 \\
109 \\
72 \\
\mathbf{2 7 9} \\
\end{array}$ & $\begin{array}{l}3,62 \\
3,52 \\
3,82 \\
3,58 \\
\end{array}$ & $\begin{array}{l}1,066 \\
1,045 \\
1,160 \\
1,106 \\
\end{array}$ & 2,402 & 0,069 \\
\hline $\begin{array}{l}\text { Genel Performans } \\
\text { Beklentisi }\end{array}$ & $\begin{array}{l}1-3 \text { y1l } \\
3-10 \text { y1l } \\
10 \text { yıl -üstü } \\
\text { Toplam }\end{array}$ & $\begin{array}{c}98 \\
109 \\
72 \\
\mathbf{2 7 9}\end{array}$ & $\begin{array}{l}3,57 \\
3,54 \\
3,61 \\
3,53\end{array}$ & $\begin{array}{l}0,612 \\
0,605 \\
0,657 \\
0,649\end{array}$ & 2,639 & 0,050 \\
\hline
\end{tabular}

HBS alt boyutlarının çalışma süresi durumu değişkeni bakımından incelenmesi Tablo 6'da verilmiştir. ANOVA testine göre HBS alt boyutlarından performans beklentisi ve efor beklentisi boyutlarında istatistiksel olarak anlamlı fark bulunmuştur. Farklılığın kaynağını belirlemek için yapılan Tukey testine göre her iki alt boyutta da 1-3 yıl ile 10 yıl -üstü gruplarının ortalamalarının farklı olmasından kaynaklandığı tespit edilmiştir.

\section{Araştırma Sonuçları ve Tartışma}

$\mathrm{Bu}$ araştırmada, Şanlıurfa ilindeki özel bir hastanede çalışan personelin hastane bilgi sistemi hakkındaki düşünceleri ve sosyo demografik özelliklerine göre hastane bilgi sistemi hakkındaki düşünceleri arasında farklılık olup olmadığı incelenmiştir. Araştırmada elde edilen sonuçlar şöyledir:

Araştırmada kullanılan anketin Cronbach Alpha $(\alpha)$ katsayısı 0,911 olarak tespit edilmiş ve anketin güvenilir olduğu görülmüştür. Hastane personelinin HBS ifadelerine verdikleri cevapların genel performans ortalamalarının genel toplamı 3,54 olarak tespit edilmiş ve hastane personelinin genel olarak HBS genel performans beklentisine katıldığı saptanmıştır. HBS alt boyutlarının ortalamalarına bakıldığında; "Performans Beklentisi” (3,96), "Efor Beklentisi" (3,51), "Sosyal Etki" (3,59) ve "Kullanım Boyutu" (3.60) alt boyutlarına katılırken, "Kolaylaştıııı Koşullar" $(3,34)$ ve "Davranışsal Niyet" (3.27) alt boyutlarında ise genel olarak kararsız oldukları görülmektedir. Gündak ve Çetin tarafından (2012) yapılan araştırmada da benzer bir sonuç elde edilmiş ve hastane personelinin HBS kullanımının orta düzeyde bulunduğu belirtilmiştir. Yılmaz ve Demirkan tarafından yapılan (2012) araştırma da ise doktor ve hemşirelerin HBS’nin genel kullanılabilirlik düzeyine karşı kararsız oldukları görülmüştür.

Araştırmada, hastanede çalışan personelin sosyo demografik özelliklerine göre yaş, cinsiyet ve medeni durum değişkenleri açısından gruplar arasında istatistiksel olarak anlamlı bir farklılık tespit edilmemiş̧ir. Hastane personelinin HBS'e hakkındaki görüşlerinde yaş, cinsiyet ve medeni durum bakımından grupların aynı görüşlere sahip oldukları görülmektedir. Uslu ve arkadaşları (2016) tarafından yapılan araştırmada hastane personelinin yaş faktörü ile HBS kullanımı arasında istatistiksel olarak anlamlı bir farklılık tespit edilmesine rağmen cinsiyet ve medeni durum açısından anlamlı bir fark tespit edilmemiştir (Uslu ve arkadaşları, 2016). Gündak ve Çetin (2015) tarafından yapılan araştırmada da cinsiyet ve yaş grupları açısından anlamlı bir farklılık gözlenmemiştir.

HBS alt boyutlarının hastane personelinin eğitim durumu değişkeni bakımından incelenmesi sonucunda "performans beklentisi" ve "HBS kullanım" alt boyutlarında istatistiksel olarak anlamlı bir fark bulunmuştur. Farklılığın lisans mezunu hastane personelinden kaynaklandığı belirlenmiştir. Lisans mezunu hastane personelinin ortalamasının her iki alt boyutta da lise/önlisans ve lisansüstü/doktora gruplarından daha düşük olduğu tespit edilmiştir. Yani lisans mezunu hastane personelinin "performans beklentisi" ve "HBS kullanım" alt boyutlarına genel olarak daha az katıldı̆̆g görülmektedir. Bunun en önemli nedeni, lisans mezunu grubunda yer alan personelin çoğunluğunun hemşire/ebe grubunda yer alan personelden oluşmasıdır. Bu gruptaki personel, hastalara sürekli bakım hizmeti sunduğu için iş yoğunluğu içerisinde HBS kullanımının ve performans beklentisinin kendilerine iş yükü çıkardığını düşünebilirler. Ayrıca hemşire ve ebelerin çoğunluğunun HBS kullanabilmek için yeterli bilgisayar eğitimi almadıkları ve hastanenin de hizmet içi eğitim vermediği için, bu konuda diğer meslek gruplarından daha düşük ortalamaya sahip oldukları sonucuna varılabilir. Çünkü literatürde Çakırlar ve Mendi tarafından (2016) yapılan araştırmada hemşirelerin büyük çoğunluğunun hemşirelik eğitiminde alınan bilgisayar derslerinin yetersiz olduğunu ifade ettikleri ve hizmet içi eğitim programlarında teknoloji kullanımının etkinliğini 
artırıcı programlar istedikleri görülmüştür. Ünalan tarafından (2016) yapılan araştırma da ise eğitim açısından gruplar arasında anlamlı bir farklılık tespit edilmemiştir.

HBS alt boyutlarının çalışma süresi durumu değişkeni bakımından incelenmesi sonucunda performans beklentisi ve efor beklentisi boyutlarında istatistiksel olarak anlamlı fark bulunmuştur. Farklılı̆ı̆ı kaynağını belirlemek için yapılan Tukey testine göre her iki alt boyutta da 1-3 yıl ile 10 yıl -üstü gruplarının ortalamalarının farklı olmasından kaynaklandığı tespit edilmiştir. 10 yıl ve üzeri grupta çalışan hastane personelinin ortalamasının daha yüksek olduğu görülmektedir. Hastanede çalışma süresi arttıkça edinilen deneyim sayesinde personelin HBS'ye daha rahat uyum sağladığı ve bu konuda tecrübeli olduğu söylenebilir. Literatürde Uslu ve arkadaşları tarafindan (2016) yapılan araştırmada benzer sonuçlar elde edilmiş ve çalışma süresi daha fazla olan grupların ortalamasının, daha az çalışan gruplara göre yüksek olduğu tespit edilmiştir. Bir diğer araştırmada ise çalışma süresi 6-10 yıl olan hemşirelerin, çalışma süresi 1-5 yıl olan hemşirelerden daha yüksek olduğu görülmüştür (Çakırlar ve Mendi, 2016).

Sonuç olarak hastanelerde sunulan sağllk hizmetlerinin etkili, kaliteli, verimli sunulabilmesi için hastane personelinin HBS'yi yüksek kullanım düzeyleri önem arz etmektedir. Ayrıca, hem dünyada hem de Türkiye'de bilişim sistemlerinin etkin kullanımı ile hasta ve sağlık profesyonellerinin çaba ve zaman israfından kaçınmak, sağlık yönetimi sürecindeki aksaklıklara çözüm bulmak ve finansal verimliliği artırmak amaçlanmaktadır (Kılıçarslan, 2018). Hastane personeli ise, araştırmada en çok performans beklentisi alt boyutundaki HBS'yi kullanmak işimdeki başarıyı arttırır (4.00), HBS işlerimi çabuk yapmama yardımcı olur (3.99), HBS iş verimliliğini arttırır (3.93) ve HBS'yi kullanmayı işimde yararlı buluyorum (3.92) ifadelerine yüksek oranda katıldıklarını belirtmişlerdir. Hastanede kullanılan HBS'nin kendileri açısından faydalı olduğunu ve işlerini yaparken kendilerini başarıya ulaştırdığını ifade etmişlerdir.

Hastane personeli, araştırmada "davranışsal niyet (3.27)" alt boyutundaki HBS'yi yoğun bir şekilde kullanmaya devam etme $(3,22)$, gelecekte HBS'yi kullanmaya devam etme (3.29) ve HBS'yi her zaman kullanma $(3,33)$ ifadeleri konusunda ise kararsiz olduklarını belirtmişlerdir.

Hastane personelinin kararsız kaldığı bir diğer alt boyut ise kolaylaştırıcı koşullardır (3.29). Kolaylaştırıcı koşullar alt boyutunda en çok kararsız oldukları ifadelerin başında sisteme destek veren ekip uzmandır (3.29) ve HBS'yi kullanmada gerekli kaynaklara sahip (3.29) olma ifadeleri gelmektedir. Hastane personelinin, hastanede HBS konusunda çalışan personelin uzmanlığı konusunda şüpheleri bulunurken, kendilerinin de çalışrken gerekli kaynaklara sahip oldukları konusunda kararsız oldukları görülmektedir. Yine hastane personeli, kullandıkları HBS'nin diğer teknolojilerle uyumlu olması $(3,30)$ ve HBS'yi kullanırken destek alacak birilerini bulma $(3,34)$ konusunda kararsızdırlar.

$\mathrm{Bu}$ sonuçlar 1şı̆̆ında şu öneriler yapılabilir:

- Sağlı alanında eğitim gören öğrencilere, günün koşullarına göre itiyacı karşılayacak kadar bilgisayar eğitimi verilmelidir.

- Hastanede çalışan personele, hastanelerde hizmet içi eğitim verilirken teknoloji kullanımının etkinliğini artırıcı eğitimler de verilmelidir.

- Hastane yönetimi, HBS konusunda çalışan personeli istihdam ederken, liyakat ilkelerine bağlı kalarak, uzman kişileri işe almalıdır.

- Hastane yönetimi, personelin kolaylıkla ulaşıp, destek alabileceği HBS uzmanı personeli 7/24 bulundurmalıdır.

- Hastane personeli, HBS konusunda ihtiyaçlarını karşılayacak gerekli kaynaklara sahip olmalıdırlar.

- Hastane yönetimi, HBS sistemini kurarken, mevcut diğer teknolojilerle uyumlu ve kullanımının kolay olmasına dikkat etmelidirler.

\section{Kaynakça}

Ak, B. (2009). Türkiye'de sağlı bilişimi, bir kişisel değerlendirme ve uluslararası bir başarı öyküsü: CorTTex. Akademik Bilişim'09 - XI. Akademik Bilişim Konferansı Bildirileri, 11-13 Şubat 2009 Harran Üniversitesi, Şanlıurfa, 333-341

Almunawar. M.N., Anshari. M., (2012) Health Information Systems (HIS): Concept and Technology, https://www.researchgate.net/publication/221710863_Health_Information_Systems_HIS_Concept_and_Technology, Erişim tarihi: 12.05 .2019

Biçer, E.B.(2018). Sağlık Kurumları Yöneticilerinin Stratejik Yönetim Tekniklerine Bakış Açılarının Ve Yaklaşım Tarzlarının Belirlenmesi: Sivas İli Örneği, Yönetim ve Ekonomi Araştırmaları Dergisi, 16 (4): 405-427.

Bilgiç. Ş., Şendir. M., (2014), Hemşirelik Bilişimi, Cumhuriyet Hemşirelik Dergisi, 3(1): 24-28

Çakırlar. A., Mendi. B., (2016) Hemşirelerin elektronik sağlı kaydı ve bilişim uygulamaları kapsamındaki bilgi ve tutumlarının değerlendirilmesi, FNG \& Bilim Tıp Dergisi 2016;2(1):32-39, doi: 10.5606/fng.btd.2016.007

Engin, M., Gürses, F. (2019). Adoption of Hospital Information Systems in Public Hospitals in Turkey: An Analysis With the Unified Theory of Acceptance and Use of Technology Model, International Journal of Innovation and Technology Management, DOI: $10.1142 / \mathrm{S} 0219877019500433$

Eriş. H., (2016) Hemşirelerin Hastanelerde Kullandıkları Elektronik Tıbbi Kayıtlar Hakkındaki Görüşleri: Şanlıurfa Örneği, Sağlık Akademisyenleri Dergisi, Vol.3, Issue 3, DOI: 10.5455/sad.13-1477551776 
Gencer, Z.T., Daşlı, Y., Biçer, E.B. (2019). Sağlık İletişiminde Yeni Yaklaşımlar: Dijital Medya Kullanımı, Selçuk Üniversitesi Sosyal Bilimler Meslek Yüksekokulu Dergisi, 2 (1): 42-52.

Gundak. İ., Çetin. H., (2015) Hastane Bilgi Sistemlerinin SUMI Yöntemine Göre Kullanılabilirlik Düzeyinin Belirlenmesi: Akdeniz Üniversitesi Hastanesi Örneği, Süleyman Demirel Üniversitesi İktisadi ve İdari Bilimler Fakültesi Dergisi, C.20, S.2, s.315-331

Hilal Uysal. H., Yıldız. M., Dinçer. M., Eybek. Z., (2017) Hemşirelik Öğrencilerinin Bilgisayar ve Bilişim Teknolojileri Hakkındaki Farkındalıklarının Değerlendirilmesi, G.O.P. Taksim E.A.H. JAREN 2017;3(3):153-162

Işık. O., Akbolat. M., (2010) Bilgi Teknolojileri ve Hastane Bilgi Sistemleri Kullanımı: Sağlık Çalışanları Üzerine Bir Araştırma, Bilgi Dünyas1, 11 (2) 365-389

Kiliçarslan, M. (2018). The Assessment and Comparison of Health Information Systems in Turkey and in the World, Avrupa Bilim ve Teknoloji Dergisi, 14 (3): 127-133.

Köksal, A., Esatoğlu. A. E. (2005). Ankara İlindeki Üniversite Ve Özel Hastanelerde Kullanılan Elektronik Hastane Bilgi Sisteminin Analizi. Ankara Üniversitesi Dikimevi Sağlık Hizmetleri Meslek Yüksekokulu Dergisi, 7(1), 53-65.

Kuperman. G. J., Spurr, C., Flammini. S., Bates. D., Glaser. J. (2000). A clinical information systems strategy for a large integrated delivery network. Proc AMIA Symp., $438-442$.

Ömürbek. N., Altın. F.G., (2009) Sağlık Bilişim Sistemlerinin Uygulanmasına İlişkin Bir Araştırma: İzmir Örneği, SDÜ Fen Edebiyat Fakültesi Sosyal Bilimler Dergisi, Say1:19, ss.211-232

Öner F. Sağlık bilişimi, Türkiye'de sağlık bilgi enformasyon sistemleri ve dijital hastaneler [Yüksek Lisans Tezi]. İstanbul: Beykent Üniversitesi; 2014

Özata. M., Aslan. Ş., (2004) Klinik Karar Destek Sistemleri ve Örnek Uygulamalar, Kocatepe Tıp Dergisi, 5: 11 - 17

Özel. H.Ö., Ürkmez. D. Ö., Demiray. S, Cebeci. Z., (2014) Hemşirelik Bilişimi ve Hastane Bilgi Yönetimi Sistemi, Ok Meydanı Tıp Dergisi, 30(3) 158-160, doi:10.5222/otd.2014.158

Sarnıkar S., Murphy M. (2009). “A Usability Analysis Framework for Healthcare Information Technology”, Working Papers on Information Systems, 9(62).

Top M, Gider O. Nurses' views on electronic medical records (EMR) in Turkey: an analysis according to use, quality and user satisfaction. J Med Syst 2012;36(3):1979-1988

Uslu. D., Toygar., Ş.A., Mansur. F. (2016) Hastane Bilgi Yönetim Sisteminin Kullanılabilirliğini Belirlemeye Yönelik Bir Araştırma, Uluslararası Sağlık Yönetimi Ve Stratejileri Araştırma Dergisi, Cilt 2, Sayı 3,

Ünalan. N., (2016) Bir Eğitim Hastanesi’nde Hastane Bilgi Sistemleri Değişim Yönetimi İncelenmesi Ve İyileştirme, Doktora Tezi, T.C. Kara Harp Okulu Savunma Bilimleri Enstitüsü Teknoloji Yönetimi Ana Bilim Dalı

Venkatesh V., Morris, M. G., Davis, G. .B. \& Davis, F. D. (2003). User acceptance of information technology: Toward a unified view. MIS Quarterly, 27(3), 425-478.

World Health Organization, (2006) Electronic Health Records: Manual for Developing Countries, WHO Library Cataloguing in Publication Data

World Health Organization, (2006) Health Information Systems, Health Metrics Network Framework and Standards for Country Health Information Systems, World Health Organization, January file://C:/Users/lenovo/Desktop/hbs\%20makale/who\%202008.pdf erişim tarihi: 12.05.2019

Yılmaz, A., Aloğlu. E. (2002). Hastane Bilgi Sistemleri. 5. Ulusal sağlık kuruluşları ve hastane yönetimi sempozyum kitabı. Eskişehir: 16-19 Ekim, 331-339

Yılmaz. M., Demirkan. A. E., (2012) Hastane Yönetim ve Bilgi Sisteminin Kullanılabilirliğinin Değerlendirilmesi, Bilişim Teknolojileri Dergisi, Cilt: 5, Say1: 3, 2012 